\title{
A case of regional migratory osteoporosis
}

\author{
J. Spierings ${ }^{1,2}$ (D) S. Bours ${ }^{3} \cdot$ H.R.M. Peeters ${ }^{1}$
}

Received: 29 June 2017 / Accepted: 21 September 2017 /Published online: 24 October 2017

(C) The Author(s) 2017. This article is an open access publication

\begin{abstract}
We present the case of a middle-aged man with three episodes of regional migratory osteoporosis of the lower extremities occurring over a period of 8 years. Symptoms included a sudden onset of unilateral bone and joint pain. After initiation of pamidronate treatment, symptoms improved significantly. Regional migratory osteoporosis is a rare, but probably underdiagnosed condition with an unclear etiology. This case illustrates the importance of recognition of the disease in order to inform the patient, start treatment, and prevent unnecessary invasive procedures. Although in literature, not much is reported about treatment strategies, our patient was successfully treated with pamidronate after failure of oral bisphosphonates.
\end{abstract}

Keywords Bisphosphonate $\cdot$ Bone $\cdot$ Metabolic bone disease . Regional migratory osteoporosis

\section{Case presentation}

A 64-year-old Caucasian man presented with severe pain in his left foot and ankle for the last 15 days. The symptoms had a sudden onset and pain increased during standing and walking. There was joint tenderness and a mild swelling of the

J. Spierings

j.spierings@umcutrecht.nl

1 Department of Rheumatology, Zuyderland Medical Centre Heerlen, Heerlen, The Netherlands

2 Department of Internal medicine, subdivision Rheumatology, Maastricht University Medical Centre, Maastricht, The Netherlands

3 Department of Internal Medicine, subdivision Rheumatology, Maastricht University Medical Centre, Maastricht, The Netherlands midfoot and ankle. He denied any antecedent injury. Further review of his medical history revealed two similar episodes of pain in his right foot and left hip, 8 and 6 years ago, respectively. The patient was severely incapacitated. A diagnosis could not be made at that time. Complex regional pain syndrome (CRPS type I) or gout in his right foot was considered. However, treatment with nonsteroidal anti-inflammatory drugs, opioids, or steroids was not effective. Eventually, his symptoms resolved after 1 year. His current physical examination demonstrated a mild swelling and tenderness of the upper area of the left foot. There was an antalgic gait and a pain-induced restricted range of motion of his left ankle and midfoot. There were no signs of synovitis or tendinitis. Examination of other joints, including the left hip and right foot showed no abnormalities. Laboratory tests including Creactive protein, erythrocyte sedimentation, full blood count, kidney function test, calcium, phosphate, vitamin D levels, and parathyroid hormone, were normal. X-rays of the left foot showed demineralization of the midfoot and talus, with preserved joint space (Fig. 1). There were no signs of a fracture. Bone scintigraphy showed hyperperfusion (Fig. 2) and increased osteoblast activity and on medical resonance imaging (MRI) bone; marrow edema was seen in these areas. Bone mineral densitometry showed osteopenia. Eight years ago, $\mathrm{X}$-rays of the right foot showed similar features of the bone of the fore- and midfoot (Fig. 3) and the left hip (Fig. 4). Both radiologic changes were normalized at current presentation. A diagnosis of CRPS-1 was dismissed since our patient did not have any sensomotoric symptoms or predisposing factors. Furthermore, taking into account the history of similar, transient attacks, regional migratory osteoporosis was considered as overall diagnosis. Treatment with calcium, vitamin $\mathrm{D}$, and oral bisphosphonates was initiated. However, after 2 months, symptoms increased and treatment was changed to intravenous pamidronate. After the first administration, pain 


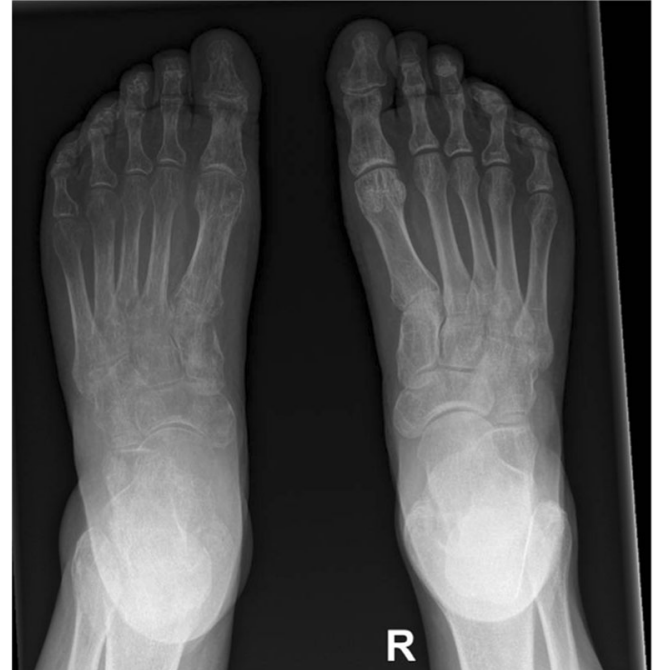

Fig. 1 Periarticular osteopenia of the tarsometatarsal (TMT) and metatarsophalangeal (MTP) joints of the left foot

decreased notably. This therapy was continued every 3 months for 9 months. A rehabilitation program was started. After 4 months, symptoms disappeared, and the patient experienced complete recovery.

\section{Discussion}

This case describes a man suffering from recurrent episodes of localized osteoporosis during 8 years' time. It took almost one

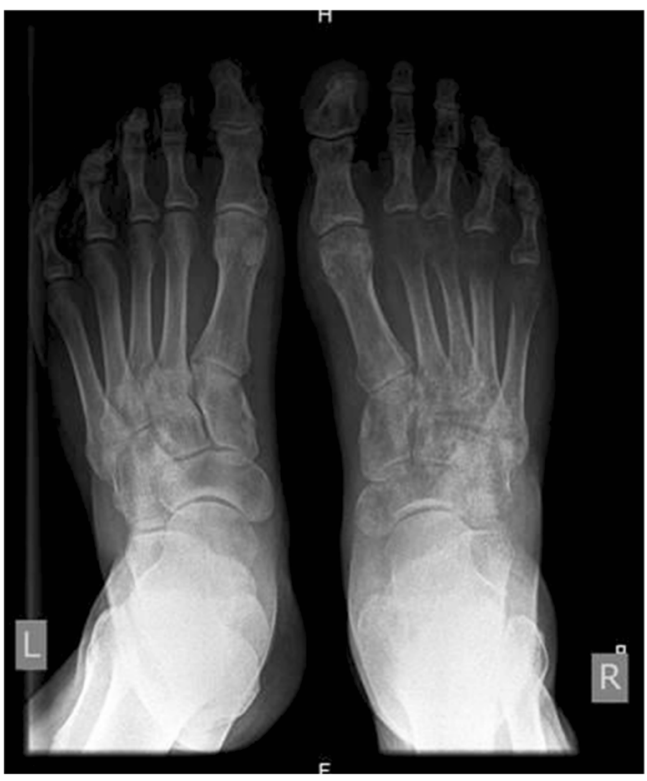

Fig. 3 Periarticular osteopenia of the TMT and MTP joints of the right foot, 8 years prior to presentation

decade to recognize the pattern that fits regional migratory osteoporosis (RMO). RMO is a rare condition. Several case reports suggest that the disease could be underreported because the clinical presentation could be misinterpreted as arthritis of CRPS-1 or diagnosed as transient osteoporosis $[1,2]$. Diabetes and Charcot foot should be considered as differential diagnosis. Also, similar conditions may be seen in patients with rheumatoid arthritis, especially when high dose or
Fig. 2 Bone scintigraphy of the lower extremities.

Hyperperfusion of the left talus, os naviculare, and several TMT joints is present

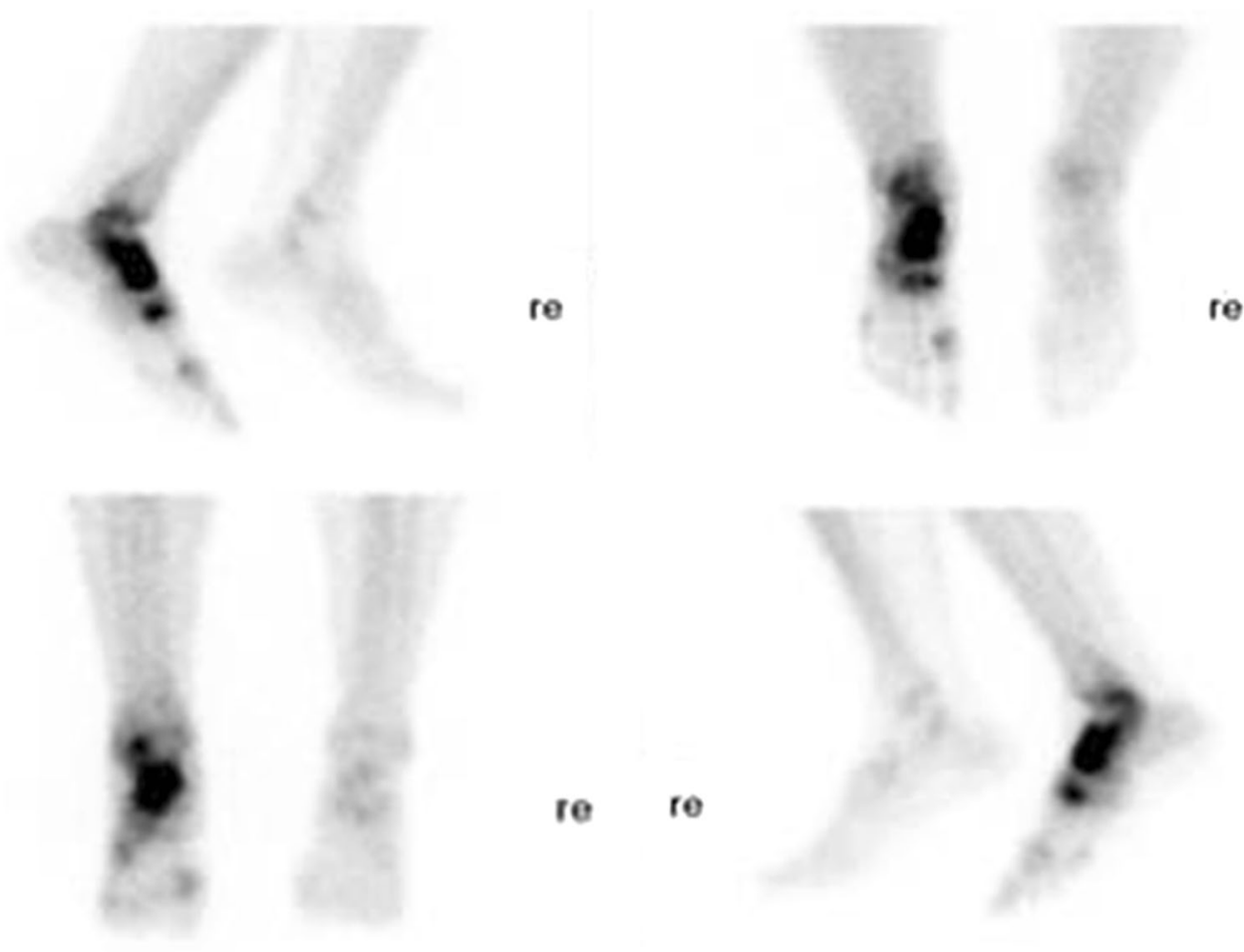




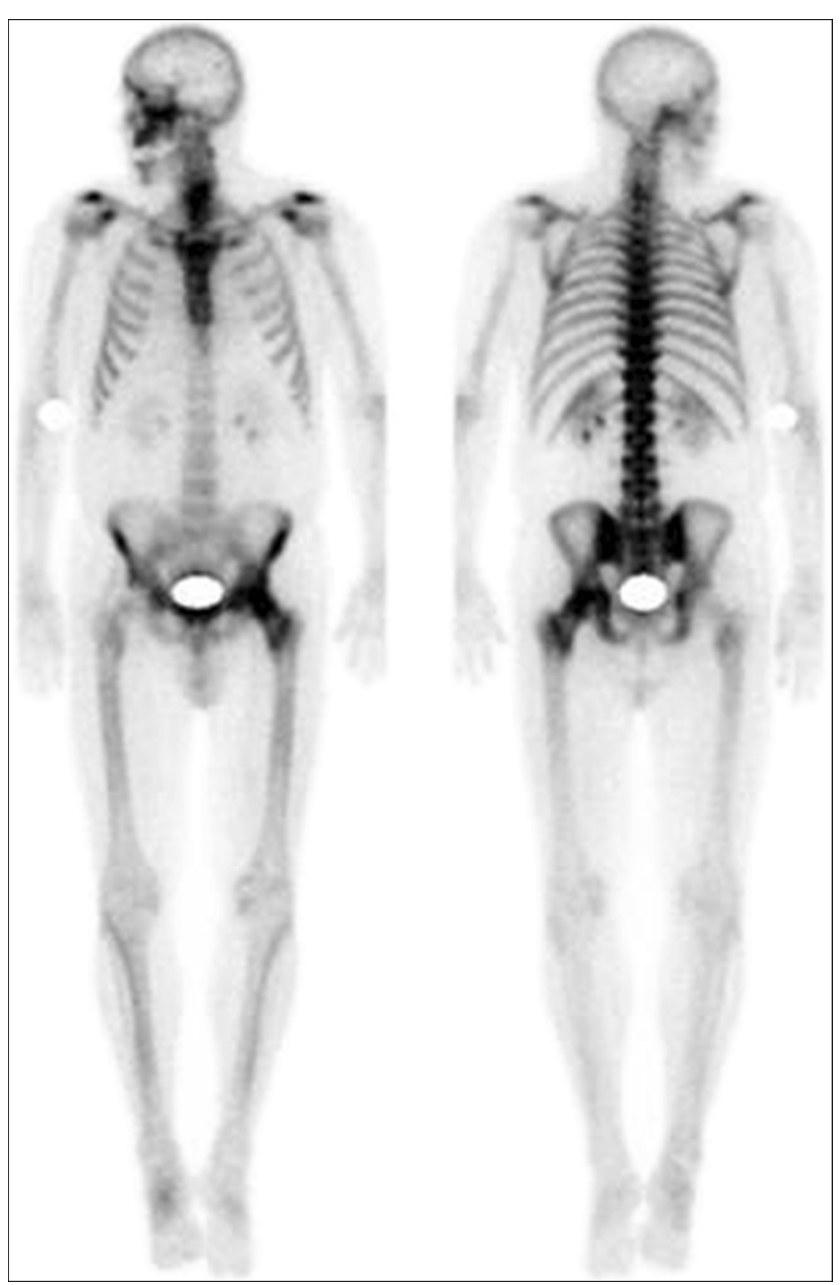

Fig. 4 Bone scintigraphy shows hyperactivity of left hip, compatible with transient osteoporosis, 6 years prior to presentation

extended corticosteroid therapy is involved. RMO may occur at several sites; although the weight bearing, lower extremities are affected most often. Mainly men in their fifth and sixth decades of life are affected [3]. Symptoms could last for 3 months till 2 years and are eventually self-limiting [4]. Time between two different events varied from 5 months to 14 years [3]. Arthralgia in a single joint is the most common clinical presentation. Symptoms are not related to trauma. There is often no or only a slight diffuse swelling of the affected joint $[3,5,6]$. As plain radiographs may remain normal at the onset of symptoms, bone scintigraphy and MRI could be helpful diagnostics $[1,7]$. Bone scintigraphy will show increased radioisotope uptake on both the early blood pool images and delayed scintigraphy $[8,9]$. MRI is characterized by bone marrow edema [10]. After a few weeks, radiographs will show diffuse or patchy demineralization of the affected bone. Eventually, density of the bone returned to normal in most patients [6]. A common feature in patients is the presence of systemic osteoporosis or osteopenia $[11,12]$. Although the pathogenesis of RMO has not been completely unraveled, this might be an important risk factor. Preexistent decreased bone density could lead to microdamage of the bone tissue. In response to microtrauma, bone metabolism, consisting of blood flow, cell turnover, and remodeling, will be increased. This response is called the regional accelerated phenomenon (RAP). In patient with RMO, it is thought that this response is increased $[1,12,13]$. It is suggested that RMO has a similar disease process as transient osteoporosis. Transient osteoporosis of the hip could therefore be considered as part of RMO [2, 12, 14]. The presented case might support this since both regional migratory osteoporosis in both feet as transient osteoporosis of the left hip occurred in the same patient. No systematic studies have been performed to determine treatment strategies. Effective symptom relief was reported in cases treated with alendronate, calcium, vitamin D, subcutaneous calcitonin, or pamidronate. However, new episodes could not be prevented with this treatment [12, 15-17].

Acknowledgements We would like to thank our patient for granting informed consent to publish this clinical case. Anonymity and confidentiality was assured at all times.

\section{Compliance with ethical standards}

\section{Conflict of interest None.}

Open Access This article is distributed under the terms of the Creative Commons Attribution-NonCommercial 4.0 International License (http:// creativecommons.org/licenses/by-nc/4.0/), which permits any noncommercial use, distribution, and reproduction in any medium, provided you give appropriate credit to the original author(s) and the source, provide a link to the Creative Commons license, and indicate if changes were made.

\section{References}

1. Toms AP, Marshall TJ, Becker E, Donell ST, Lobo-Mueller EM, Barker T (2005) Regional migratory osteoporosis: a review illustrated by five cases. Clin Radiol 60(4):425-438

2. Uzun M, Ayhan E, Beksac B, Karaman Ö (2013) Regional migratory osteoporosis and transient osteoporosis of the hip: are they all the same? Clin Rheumatol 32(6):919-923

3. Cahir JG, Toms AP (2008) Regional migratory osteoporosis. Eur J Radiol 67(1):2-10

4. Lakhanpal S, Ginsburg WW, Luthra HS, Hunder GG (1987) Transient regional osteoporosis. A study of 56 cases and review of the literature. Ann Intern Med 106(3):444-450

5. Swezey RL ( 1970 Nov) Transient osteoporosis of the hip, foot and knee. Arthritis Rheum 13(6):858-868

6. Langloh ND, Hunder GG, Riggs BL, Kelly JP (1973) Transient painful osteoporosis of the lower extremities. J Bone Joint Surg Am 55(6):1188-1196

7. Gil HC, Levine SM, Zoga AC (2006) MRI findings in the subchondral bone marrow: a discussion of conditions including transient osteoporosis, transient bone marrow edema syndrome, SONK, and shifting bone marrow edema of the knee. Semin Musculoskelet Radiol 10(3):177-186 
8. Kim SM, Desai AG, Krakovitz M, Intenzo CM, Park CH (1989) Scintigraphic evaluation of regional migratory osteoporosis. Clin Nucl Med 14(1):36-39

9. Tannenbaum H, Esdaile J, Rosenthall L. Joint imaging in regional migratory osteoporosis. J Rheumatol;7(2):237-44

10. MacLean S, Kumar R, Tr F, Clough TM, Jenkins JP, Barrie JL, Wood PLR (2009) Transient regional migratory osteoporosis in the ankle and foot: a case series and literature review. Foot Ankle Online J 2(10): 1

11. Banas MP, Kaplan FS, Fallon MD, Haddad JG (1990) Regional migratory osteoporosis: a case report and review of the literature. Clin Orthop Relat Res 250:303-309

12. Trevisan C, Ortolani S, Monteleone M, Marinoni EC (2002) Regional migratory osteoporosis: a pathogenetic hypothesis based on three cases and a review of the literature. Clin Rheumatol 21(5): $418-425$
13. Cano-Marquina A, Tarín JJ, García-Pérez MÁ, Cano A (2014) Transient regional osteoporosis. Maturitas 77(4):324-329

14. Asadipooya K, Graves L, Greene LW (2017) Transient osteoporosis of the hip: review of the literature. Osteoporos Int 28(6):1805-1816

15. Schapira D, Gutierrez G, Mor M, Nahir AM (2001) Successful pamidronate treatment of severe and refractory regional migratory osteoporosis. JCR J Clin Rheumatol 7(3):188-190

16. Ferriero G, Ozcakar LFF (2008) Regional migratory osteoporosis in older adults: a new twist to an old disease. J Am Geriatr Soc 56(4): 769-772

17. Emad Y, Ragab Y, El-Shaarawy N (2012) Transient osteoporosis of the hip, complete resolution after treatment with alendronate as observed by MRI description of eight cases and review of the literature. Clin Rheumatol 31(11):1641-1647 